\title{
Experience of developing Twitter-based communities of practice in higher education
}

\author{
Bex Lewis ${ }^{\mathrm{a}}$ and David Rush ${ }^{\mathrm{b} *}$ \\ ${ }^{a}$ CODEC (Centre for Christian Communication in a Digital Age), St. John's College, \\ Durham University, Durham, UK; ${ }^{b}$ Learning and Teaching Development Unit, University of \\ Winchester, UK
}

(Received 20 April 2012; final version received 13 March 2013)

\begin{abstract}
This article presents the results of a case study of the use of a microblogging tool by a university academic to increase their knowledge and experience of social media for educational purposes. The academic had the role of digital steward in a university and attempted to use microblogging (Twitter) to increase professional contacts within the framework of a community of practice. Several types of data were collected and analysed. These included the structure of the network arising from the links formed with others by microblogging, the similarity of stated interests between the academic and others in the network, and the contents of postings such as their external references. It was found that a personal network had been established, with some of the characteristics of a community of practice. The activity demonstrated the utility of social media in supporting the professional development of academic staff using technology.
\end{abstract}

Keywords: community of practice; technology steward; microblogging; social media; professional network

\section{Introduction}

Over the recent years there has been a significant shift in people's usage of computers. Once, the personal computer was seen as a tool for the preparation of documents and searching the Internet. Interaction with others was mainly via email. Now interaction is, for many, the primary purpose of their desktop computer, laptop or mobile phone. The computing device provides an entry into the world of social media. The types of interaction and the systems used for it have often been aggregated into the notion of web 2.0 (O'Reilly 2005). In higher education, there have been many attempts to apply social media to directly support teaching and for other purposes (Conole and Alevizo 2010). One possibility is to use social media itself to bring together academic staff as they come to terms with the implications of social media for their pedagogy. This is the aspect we concentrate on in this article.

In higher education institutions, the take up of new forms of technology for teaching and learning is often led by a few innovators, first exploring the technology and then introducing it into practice. They act, formally or informally, as a focus for that introduction as they help others to follow in their footsteps. In doing this, they themselves seek support as they improve their expertise, but in their own institutions

*Corresponding author. Email: david@dkrush.co.uk 
there may be few who can provide this. So they try to share the experience of those with a similar role in other institutions. Traditionally this has been done through face-to-face meetings such as conferences. Now the widespread use of social media provides many opportunities for the exchange of ideas and information. The two blended together is a strong combination.

Here, we explore the utility of social media for this purpose within a framework that has two elements. First, there is the extent to which the technology facilitates and promotes interaction. Of particular interest is whether it can be used as the basis of attempts to build a community of practitioners, those who share a common interest and wish to exchange ideas and their experience. This issue may be explored with the well-established concept of a Community of Practice (CoP) (Wenger 1998), described in more detail below. Second, the practitioners who are promoting the use of digital technology within their institutions may be thought of as technology stewards (Wenger, White, and Smith 2009), defined as "people with enough experience of the workings of a community to understand its technology needs, and enough experience with or interest in technology to take leadership in addressing those needs". An alternative, and more accurate, designation would be digital steward, thus taking the focus away from the technology itself.

A related issue is the nature of the technology underpinning a community. Asynchronous communication by email is now taken for granted and other forms of asynchronous communication such as the forum, wiki and blog are also being used in higher education (HE) for teaching and staff development. There is a particular focus on the use of providers external to the institution such as Facebook and Twitter. More specialised types of communication such as the sharing of bookmarks and syndication are also readily available. A discussion of the issues that arise in the use of such systems can be found at Franklin and van Harmelen (2007). The case study presented here used the Twitter microblogging service.

Subsequent sections consider various manifestations of the idea of a $\mathrm{CoP}$, as a way for someone in $\mathrm{HE}$ to enhance their capability to promote technology in teaching through professional development via social media. Results are then presented of a case study of an attempt to initiate and develop a community of practitioners by the use of a social media tool.

\section{Background to the investigation}

The term CoP was first used by Lave and Wenger (1991) and achieved wider currency through Wenger's later book (1998). A CoP may be briefly characterised as a group of practitioners who interact with each other to share their expertise about some aspect of their practice. They jointly develop and learn about a shared repertoire of resources. The people in the community can be located near to each other, in the same department or organisation; they can be widely spread, perhaps across the globe. They can communicate face-to-face, by letter or telephone; in recent years they are likely to communicate electronically. There have been applications of the notion of a $\mathrm{CoP}$ in a various learning contexts, including a practical guide to applying the ideas in a business context within a corporation (Wenger, McDermott, and Snyder 2002). Cox (2005) analysed these early contributions and established that the ambiguity inherent in "community" and "practice" leads to a term that has been applied to very different learning situations, ranging from the individual's search for identity to the organisational need for dissemination of knowledge. 
Where community membership is not automatically defined, for example, by employment in a department, there are several approaches to the identification of communities. They are based upon a network model in which individuals are represented as network nodes and interactions as links between nodes. Intuitively a community is that part of the network where the linkages have the highest density, but there is no one definition of what is meant by a community in a network. So the various algorithms which detect communities in networks (Fortunato 2010) each give their own result. An example of identifying informal knowledge networks in an organisation is Jonkeren and Huysman (2006) which traces links through the identification of topics of interest, followed by an interview about interactions.

One simple approach to identifying communities in a network is through the use of cliques. A clique in a network (Hanneman and Riddle 2005) is a set of nodes, all of which are directly connected to all other nodes in the set. A community may be defined as a maximal clique, that is, a clique that is not a subgraph of any other clique. This rather stricter definition of community than usually adopted may be useful in the sparser networks considered in the case study below.

A term related to CoP is network of practice (Brown and Duguid 2001; Wasko, Tiegland, and Faraj 2009). Although such networks share some characteristics with CoPs such as a central repository of knowledge, they are significantly looser, typically with participants who have not met directly. Members share an interest in their practice but membership is voluntary and open to all. This fluidity of structure is emphasised by Wasko, Tiegland, and Faraj (2009), who concentrate on electronic networks of practice such as forums and discussion groups. The network forms, either directly or indirectly, as members respond to each others' posts.

There have been several demonstrations that CoPs and networks of practice can develop through electronic communication. Murillo (2008) analysed data from a large number of Usenet groups to see whether any group constituted a virtual CoP. Using secondary traits indicative of dimensions that Wenger specified as identifying CoPs, several virtual CoPs were identified in Usenet groups. Wasko, Tiegland, and Faraj (2009) explored the characteristics of a network of practice based on a professional association bulletin board. Two results in particular are of relevance here: electronic networks of practice may be a viable alternative to a face-to-face $\mathrm{CoP}$ and there will be a critical mass of active participants in such a network.

The two volumes edited by Kimble, Hildreth, and Bourdon (2008), concentrating as they do on CoPs in education, contain several articles of relevance to this study (e.g. Little 2008; MacDonald and Hewling 2008; Schwier and Daniel 2008). It is notable that the majority of these articles discuss CoPs that are either intrainstitutional or formally established. However, some have the same focus as this article in that they consider CoPs informally established across institutional boundaries using electronic means of communication.

To be effective in the role of digital (technology) steward (Cochrane 2010; Narayan and Baglow 2010; Wenger, White, and Smith 2009), a person needs on the one hand to be capable with the technology, experimenting with innovations to explore their utility, whilst also aware of the various ways in which those innovations may be brought into the practice of the community. To achieve this effectiveness, the steward needs to devote time to increasing their own knowledge and abilities in the technological and community aspects of the role. But the role of a technology steward within an HE institution is often an isolated one as they experiment ahead of others with the latest technology for teaching. A person given such responsibilities 
will seek to increase their knowledge of the technologies they are promoting through interaction with those with a similar role in other institutions. They can achieve such contact within the context of a formal or informal community. Although the development of a community may be achieved in part through activities that are faceto-face, particularly when the community is wholly within a geographically distinct organisation, the focus of the investigation reported here is to achieve this purpose by means of the social media tools that are being explored and promoted. The resulting electronic community will have the characteristics of a network of practice.

\section{Creating a social media community}

A digital steward might try to develop his/her community involvement with other digital stewards by various technological means. Here, we have focused on microblogging because of its increasing use and because it is not yet widely accepted as a useful tool for practising educators. By a microblog we mean an internet-posted, generally accessible short statement. The statement may indicate the poster's status or may be information deemed to be of general interest. Many social media tools provide facilities for microblogging, but here we concentrate on Twitter (2010b). This enforces a comparatively short limit to its posts - called "tweets" - of 140 characters. Its advantage for this investigation is that although it offers additional facilities, such as direct person-to-person messages, its focus is on posting and reading messages. Tweets are directly visible to a user's followers and a user will see the tweets of those users he/she has chosen to follow (called "followees" below, to avoid the more ambiguous term "friends"). The number of followers and followees for certain types of user can run into many thousands but more typically the number is in the low hundreds. The entry box for tweets is headed "What's happening?", emphasising the intention that users should post messages about their current status. In practice, postings have various purposes. Some are about people's private lives, others fulfil an academic or professional purpose.

There have been several studies of the general use of Twitter (Java et al. 2007, RJMetrics 2010) revealing changing patterns of usage over time. In HE, its use has been mainly for teaching (Dunlap and Lowenthal 2009; Kassens-Noor 2012) but more recently there have been investigations of its use for staff communication and development. Ford, Bowden, and Beard (2011) created a Twitter account to distribute the latest legal news to staff and law students within their institution. It became popular with legal professionals outside that institution. Gruzd, Wellman, and Takhteyev (2011) describes the development of a Twitter network of an individual academic and demonstrates that according to Jones's (1997) criteria a "virtual settlement", essentially a community of academics interested in a specific topic, has been formed. The community consists mainly of people who had links before they were on Twitter. The community artefacts created by the members were considered to be the follower-followee relationships and their postings.

\section{Building a personal network}

A digital steward wishing to interact with other digital stewards can join existing networks based on online forums and wikis. Alternatively, by joining social media networks, he/she can try to create a personal network of practice. That is the approach reported here - to target those with similar interests who are using a 
particular social media system. It may be that those using that system will be attracted to the idea of joining an emergent informal community. There will certainly be no question as to how best to introduce them to communication technology. This is essentially the method adopted by Gruzd, Wellman, and Takhteyev (2011).

A network of practice established through technology-based social media can be assessed in a various ways (Gruzd, Wellman, and Takhteyev 2011; Wasko, Tiegland, and Faraj 2009). Characteristics of interest include size of membership; extent and nature of interaction; artefacts created; and variation of these over time. For a network of personal connections of an individual created with a microblogging system such as Twitter, the number of followers and followees gives the size of the network. Whether or not a community has been created must be judged by more than those simple numbers. From the structure of the network those people connected to the digital steward and to each other may be identified. They constitute a closely knit group, in a topological sense. They are also a maximal clique and so may be classified as a community, as previously described. Another possible way of identifying communities in the network is to look for similarities in the self-declared personal descriptions (profiles) that such networks provide. Both approaches have been used in the case study reported below.

The research methodology employed was a narrative case study (Cohen, Manion, and Morrison 2007) based on the professional practice of one of the authors (BL). This author's role as a digital steward was to support innovative uses of information technology (IT) for teaching in a small university. For the university's central IT department, the development of IT for teaching was not seen as a high priority. The author therefore operated independently and had few collaborators within the university. Consequently, as she developed a social media presence, she used it to make contact with similarly placed digital stewards in other universities. The availability of the resulting data provided the opportunity for a case study investigation of the development of her professional network on Twitter. The main research issue was whether using Twitter in this way could result in a network of practice of utility in her work as a digital steward, recognising that Twitter was not designed for use in this way. This is in contrast to the case study of Gruzd, Wellman, and Takhteyev (2011), where the network was developed by an academic researcher. The characteristics of the network in terms of size, connectivity, attributes of members and contents of postings were to be identified.

\section{Development and structure of the network}

A Twitter network based on an individual account can be characterised by several factors such as the number of links to other accounts; the number of links of those linked accounts; the similarity of interests of the linked accounts to those of the root account; and such graph-theoretic measures as the number of cliques.

The starting point is to determine the number of followers and followees. These can be established by programming using the Twitter API (Twitter 2010a) or alternatively with several available web applications such as FriendOrFollow (2010). The numbers in Table 1 were obtained by program (Russell 2011). Account (a)drbexl was established for this research; the other accounts are included for contrast.

The distribution of these three numbers gives a simple way of characterising an account. An account with a high proportion of "followers but are not followed back" 
Table 1. Number of related accounts for three Twitter accounts.

\begin{tabular}{lccc}
\hline Accounts & @drbexl & accountB & accountC \\
\hline Followed - but do not follow back & 876 & 53 & 7 \\
Followed and follow back & 801 & 69 & 1111 \\
Followers but are not followed back & 537 & 26492 & 6096 \\
\hline
\end{tabular}

is of interest to many (an authority account), but a significant proportion of reciprocal following is needed for social interaction. If the proportion of the "Followed but do not follow back" category is significant, this may be an indication of an account that is trying to create links with others. accountB would seem to be an authority account, @ drbexl to be seeking to increase its social interaction whilst accountC lies somewhere in between.

The type of network of contacts aimed for determines the methods used to build it. In developing a network of professional contacts, the objective was to find Twitter users with similar interests and concerns and to engage with them through the sharing of information. This is a very different objective from, say, that of a company promoting itself by getting its message across to the largest number of followers with little concern about feedback. For the individual professional educator, two-way communication with peers is the primary need, so rather than have a large number of followers and followees the aim is to have a number of others with whom one is engaged about topics of interest.

Choosing people to follow and getting them to follow you has become a focus of activity on Twitter. Many ways of doing it are advocated, but they are often aimed at using Twitter as a marketing tool. In creating an environment of professional engagement, the relevance of the interests of one's followers and followees is more important than their number. This guides the strategy for increasing the number of contacts. Information about people who it might be useful to follow can be gleaned from various sources. Commercial and semi-commercial tools such as Twellow and Tweet Adder will find Twitter accounts with specified characteristics such as profiles containing particular words. A search engine such as Google can be used to extract similar information from profiles, albeit using somewhat complex search terms (Calishain 2009). Since the openness of Twitter allows one to list the followers of other users, their follower lists can be checked for relevant users (known as piggybacking). In Twitter, there are communal activities for recommending users to follow, such as follow friday, the idea being to include the hashtag \#followfriday in a tweet of recommendation. The Twitter system itself offers suggestions of people to follow based on (unpublished) measures of similarity of interest. Most of these methods were tried over several months in building a follower base. Many of the added accounts were of marginal relevance, but following those posting hashtags associated with conferences of interest produced a good proportion of satisfactory accounts.

Several studies have found that the average number of followers of a Twitter account is less than 200 (for example, estimates have been RJMetrics (2010) - 27 in January 2010). By contrast, the average number of followers of @drbexl's followers is 10,465 ; the median is 900 ; and $60 \%$ of users have more than 500 followers. For an approximately power law distribution, the average is not a sensitive indicator but this large difference shows that the followers of @ drbexl are not typical Twitter accounts. They are well established users as is shown not only by the number of their followers 
but also by the average length of time since their accounts were created. This is 663 days.

The relationship between a Twitter account and the accounts of its followers can be explored through the similarity of interests between them. Each account can publish a profile. As an example that for @drbexl was:

Experimenter with social media, Blended Learning Research @ Unis of Winchester \& Durham (CODEC), Digital Literacy enthusiast: HE, SMEs, Christianity @drbexl http:// digital-figerprint.co.uk

The corresponding profiles of friend (both follower and followee) accounts were obtained via FriendOrFollow and checked for similarity, to see if the same terms occurred in both profiles. The results obtained are listed in Table 2.

At the time of this investigation there were 673 friends. These raw results show that one of the categories in @drbexl's profile, "Social media", is shared by a significant number of friends. Other profile interests are not shared by many. Of course, a person may have an active interest in a subject without putting it in their profile. For example, elearning, a topic that includes blended learning, is a topic of considerable interest to the account owner of @drbexl, but the more specialised subtopic of blended learning was used in the profile. The results show that a significant number of friends also share this interest. But another of @drbexl's interests not in the profile, "learning technology", was not shared by many friends.

As categorisation of a profile solely from the occurrence of a keyword is inherently limited, the profiles were placed in broader categories, defined after reading all the statements. These reflected @drbexl's professional interests and the intentions manifested in the profiles. The derived categories are listed in Table 3.

The majority of the profiles $(69 \%)$ fall into categories 4 and 6 , offering no immediate evidence that they share an interest with@drbexl. Those in categories 1-3, 5 and 7, that is, the categories which relate most closely to @drbexl's interests, constitute $24 \%$ and categories $8-13$, that is, relevant but general constitute $8 \%$.

The network of followers of @ drbexl is an ego network, that is, all accounts are followers of the one root account. But to assess whether @ drbexl is part of a network sharing her interests, it is necessary to examine the interconnectedness of the followers themselves, that is, the extent to which they follow each other. There are many measures of network connectedness; the one we use here is the amount of clique formation. A clique in a network (Hanneman and Riddle 2005) is a set of nodes (accounts here) all of which are connected to all other nodes in the set. The network was analysed for cliques using the Python networkx package. As the root account, @drbexl is a member of every clique. There are many cliques $(86,466)$ but most are trivial, such as the two account sub-networks. More important are the maximum cliques; the maximum size is 24 and there are 44 of these. Each of these cliques represents a group of 24 accounts all of whom are following each other. Crucially, there is an extremely strong overlap between these largest 44 cliques. There

Table 2. Word occurrence in profiles.

\begin{tabular}{|c|c|c|c|c|c|c|}
\hline $\begin{array}{l}\text { "Social } \\
\text { media" }\end{array}$ & $\begin{array}{l}\text { "Blended } \\
\text { learning" }\end{array}$ & $\begin{array}{l}\text { "HE" or } \\
\text { "Higher } \\
\text { education" }\end{array}$ & $\begin{array}{l}\text { "Digital } \\
\text { literacy" }\end{array}$ & $\begin{array}{l}\text { "Christian" or } \\
\text { "Christianity" }\end{array}$ & $\begin{array}{l}\text { "Elearning" or } \\
\text { "E-learning" }\end{array}$ & $\begin{array}{l}\text { "Learning, } \\
\text { technology" }\end{array}$ \\
\hline 73 & 3 & 10 & 3 & 11 & 53 & 7 \\
\hline
\end{tabular}


Table 3. Derived profile categories.

\begin{tabular}{|c|c|c|}
\hline & Categorisation of profiles - assigned meaning & $\begin{array}{l}\text { Number of } \\
\text { statements }\end{array}$ \\
\hline 1 & e-Learning/e-learning/blended learning - contains one of these & 55 \\
\hline 2 & Social media/social web/social network(ing) - contains one of these phrases & 54 \\
\hline 3 & $\begin{array}{l}\text { Learning technology/learning technologist/learning technologies/educa- } \\
\text { tional technology - contains one of these phrases }\end{array}$ & 21 \\
\hline 4 & $\begin{array}{l}\text { Personal details - gives details of self, rather than any of specific words } \\
\text { sought or from an organisation (the "person" being the organisation) }\end{array}$ & 292 \\
\hline 5 & $\begin{array}{l}\text { Christian - includes christian/christianity but also could be an indication of } \\
\text { christian interest without mentioning either of these words }\end{array}$ & 19 \\
\hline 6 & $\begin{array}{l}\text { Offering services - can be trying to sell, indicating the availability of a service } \\
\text { or simply providing information }\end{array}$ & 143 \\
\hline 7 & $\begin{array}{l}\text { Digital literacy - contains this phrase } \\
\text { [following relevant categories are more general and also occur] }\end{array}$ & 1 \\
\hline 8 & Education & 19 \\
\hline 9 & Training & 3 \\
\hline 10 & Learning & 22 \\
\hline 11 & Coaching & 1 \\
\hline 12 & Consulting & 1 \\
\hline \multirow[t]{2}{*}{13} & Technology & 4 \\
\hline & Total & 635 \\
\hline
\end{tabular}

Note: Not all accounts include a profile, hence the total is less than the total number of friends.

are 14 accounts common to all 44 cliques and the number of distinct accounts in the 44 cliques is only 37. This is evidence that within the set of followers of @drbexl, there is a group with enough commonality of interest to find it worthwhile to follow each other. As followers of @ drbexl, they also share enough of each other's concerns and background to choose to follow the same people. This could be interpreted as the @ drbexl account having attracted a cohesive group.

This is reinforced by an examination of the location of the accounts as given in their profiles. These show that in 36 out of the 37 accounts, the account holder is located in the United Kingdom. The 37th account does not reveal a location. So although there is the possibility of being part of a group of significant size that spans the globe, in this case the professional network clusters within the national geographic boundaries of the root account, perhaps reflecting a commonality not only of interest but also having the chance to meet face-to-face.

\section{Interactions in the network}

The 140-character limit of tweets dictates message style. Sometimes messages are terse statements, complete in themselves (example - "toast for breakfast"). More usually, and usefully, the message is given significance by external references, serving various purposes. One possibility is a link to a web page, allowing a user to draw attention to a website of interest or perhaps to a personal blog. The hashtag (a word or phrase preceded by the \# character) has become core as a mechanism for communicating a shared interest. For example, tweets might include a hashtag of the acronym of the name of a conference so that attendees searching on that hashtag could then read tweets of immediate relevance. Other users can be mentioned simply by preceding their user name with an @ character. In this way, public messages can 
be sent and attention drawn to the tweets of individual users. Tweets can also be reposted (retweeted).

Cursory observation shows that most tweets include some form of external reference and that individual users' tweets often manifest a particular pattern of reference. In the case of @ drbexl, the counts in Table 4 were obtained for an 8-month period.

The very small proportion of tweets without any external references shows the emphasis of the account holder on communication. An individual tweet may have any combination of hashtags/user mentions/URLs. A simple message might start with a single user mention, the user to whom the message is directed. The message itself might refer to a URL and use a hashtag to provide a reference point. In this way, a typical tweet derives its meaning from several external references. It is not surprising then that the average number of references is 1.87 per tweet.

Tables 5 and 6 give the frequencies of occurrence of the most frequently occurring hashtags and user mentions, respectively, for each of the months in an 8-month period. The frequencies of rows not included drop off rapidly to only a single occurrence. In both of these tables, there is a distinct variation with time. For example, the first 5 hashtags in Table 5, all related to conferences, have a sharply defined peak in the month in which the conference took place. Other hashtags of a more general nature such as e-learning and SocialMedia appear at a lesser frequency but throughout the period. User mentions show a somewhat different time profile. There are some accounts that appear each month, reflecting regular interaction. Other accounts with a high frequency in a single month also relate to conferences.

On examining the two tables in more detail, an interaction between hashtags and user mentions is revealed. For example, the hashtag \#tdc11 relates to a conference through which the author interacted extensively via Twitter with the holder of account @vickytnx, who has never been met face-to-face. This pattern of initial contact via a conference hashtag followed by regular interaction is shown in the tables in another way. In the cases of @timbuckteeth and@jamesclay, they were first contacted at conferences several months before the period covered by the tables.

Analysing the frequencies of words not emphasised as hashtags or user mentions can also be informative. Table 7 gives the frequencies of certain selected words and phrases in tweets for the same 8-month period. Variant spellings and capitalisations have been aggregated into a single entry. The results show that the content of the tweets includes references to many of the topics in which the account holder has professional interests. Thus, the hashtag mechanism aids a sharing of context, whereas the word frequencies highlight the concerns of the poster. There are also references to other social media sites such as Facebook and YouTube, indicating that the use of one social media site, Twitter, does not limit the account holder's personal community to just that site. There is a brief discussion on this in the following section.

Table 4. Tweet counts.

\begin{tabular}{lcc}
\hline Tweet count & With & Without \\
\hline Hashtags & 1835 & 1270 \\
User mentions & 2446 & 659 \\
URLs & 1528 & 1577 \\
Count of tweets with none of the above & 19 & \\
Total number of tweets & 3105 & \\
\hline
\end{tabular}


Table 5. Counts of most frequently occurring hashtags.

\begin{tabular}{|c|c|c|c|c|c|c|c|c|c|}
\hline Hashtag & Oct & Nov & Dec & Jan & Feb & Mar & Apr & May & Total \\
\hline pelc11 & & & & 7 & 1 & 2 & 575 & & 585 \\
\hline $\operatorname{tdc} 11$ & & & & & & & & 544 & 544 \\
\hline $\mathrm{sm} 4 \mathrm{sc}$ & & 115 & 3 & & & & & & 118 \\
\hline jiscel10 & 1 & 107 & & & & & & & 108 \\
\hline jiscexperts 11 & & & & & & 82 & & & 82 \\
\hline monkdev & & & & & & & & 46 & 46 \\
\hline tmpelc11 & & & & & & & 24 & & 24 \\
\hline jiscassess & & & & & & 21 & & & 21 \\
\hline likeminds & 8 & 2 & & & & & 1 & & 11 \\
\hline e-learning & 2 & & & 2 & 2 & 1 & 1 & 2 & 10 \\
\hline pelc11mob & & & & & & & 9 & & 9 \\
\hline pelcmob & & & & & & & 9 & & 9 \\
\hline SocialMedia & 2 & 2 & 1 & & & 1 & 2 & 1 & 9 \\
\hline
\end{tabular}

\section{Discussion}

Twitter was not meant for building communities. Its original design - 140 character limit; postings accessible for a short time; and its prompting "What's happening" were focused on immediate responses amongst those who already knew each other. But its enhancements such as improved search and the adoption by its users of conventions such as the hashtag and "@" symbol for communication have provided capabilities which can be used for conversation and collaboration (Gruzd, Wellman, and Takhteyev 2011; Honeycutt and Herring 2009). This combination of improved facility and user flexibility has created an environment in which networks and communities, albeit of a restricted kind, can flourish as is shown by our results.

The approach adopted here to the exploration of community formation has clear limits. It does not use one of the many different definitions of community in the literature (Fortunato 2010) but identifies a small group of people who are densely linked to each other by virtue of membership of many maximal cliques. In that

Table 6. Counts of most frequently occurring user mentions.

\begin{tabular}{lccccccccc}
\hline Hashtag & Oct & Nov & Dec & Jan & Feb & Mar & Apr & May & Total \\
\hline digitalfprint & 1 & 21 & 5 & 4 & 3 & 6 & 50 & 31 & 121 \\
timbuckteeth & 3 & 10 & 9 & 10 & 6 & 9 & 61 & 5 & 113 \\
$\begin{array}{l}\text { TheNextWeb } \\
\text { bigbible }\end{array}$ & 1 & & & & & & & 81 & 82 \\
jamesclay & 6 & 22 & 5 & 7 & 2 & 5 & 11 & 17 & 72 \\
dajbconf & 25 & 6 & 2 & 1 & 16 & 10 & 1 & 67 \\
$\begin{array}{l}\text { ThinkingDigital } \\
\text { vickytnz }\end{array}$ & & 1 & & 2 & & 1 & 10 & 49 & 59 \\
drbexl & 1 & 5 & 4 & 5 & 4 & 10 & 10 & 87 & 53 \\
Jas & & 1 & 4 & 1 & & 1 & & 37 & 47 \\
$\begin{array}{l}\text { simfin } \\
\text { chickensaltash }\end{array}$ & 1 & 1 & & & & & 29 & 13 & 43 \\
pmphillips & 1 & 3 & & 2 & & 2 & 3 & 29 & 40 \\
$\begin{array}{l}\text { vahva } \\
\text { andyjb }\end{array}$ & 3 & 11 & & & & & 20 & 3 & 37 \\
sarahknight & & 1 & 1 & 1 & & 2 & 31 & & 36 \\
$\begin{array}{l}\text { Documentally } \\
\text { Timeshighered }\end{array}$ & 1 & 2 & & & 1 & 15 & 5 & 2 & 36 \\
& 6 & 5 & & 1 & 3 & 5 & 2 & 7 & 29 \\
\hline
\end{tabular}


Table 7. Word and phrase frequencies.

\begin{tabular}{lc}
\hline Word or phrase & Frequency \\
\hline Social & 253 \\
Social media & 134 \\
Social web & 2 \\
Network & 44 \\
e-Learning & 64 \\
Twitter & 138 \\
Facebook & 77 \\
YouTube & 11 \\
Technology & 39 \\
Conference & 33 \\
Online & 76 \\
Offline & 10 \\
Workshop & 10 \\
Digital & 270 \\
Future & 42 \\
Mobile & 48 \\
Apps & 32 \\
\hline
\end{tabular}

respect, the structure of the group will have the characteristics of a community produced by the Clique Percolation Method (Palla et al. 2005) which is based on overlapping k-cliques. Finding users with similar profiles gives an indication of community formation and does not seem to have been done before. However, the measures of similarity used here are relatively crude and would not scale to larger networks. Within a community there is interaction, which in Twitter manifests itself as tweets addressed to other users (via the @ mechanism). Not following these interaction patterns was another limitation of this study. This study is of usage over a relatively short period of time. A longitudinal study following the evolution of this network of practice over several years would have been of interest, although continual changes in the facilities provided by Twitter might make this problematic.

Nevertheless, the results have shown that for professional development in HE an individual can build a useful community based upon Twitter. The author's (@drbexl) ego network has been shown to contain a relatively small number who share her interests and another group who are all linked together. Although not meeting all the requirements of Wasko, Tiegland, and Faraj (2009) for a network of practice and still less those of Wenger (1998) for a CoP, it has been shown to constitute a useful capability for someone wishing to enhance their professional development in the use of technology for teaching. The activity of operating the account has been of value to the holder in her professional life, through the immediate sharing of information and making contacts which have subsequently developed into longer lasting relationships and collaborative working. There has been interplay between electronic and face-toface communication, and fruitful discussions at conferences because of a background of understanding established through initial contact via Twitter. Conversely, there has also been useful electronic interaction with those who could not be met face to face.

The Twitter account was not the only means by which attempts were made to build a personal network. There was also a Facebook page and a blog. These facilities could communicate directly through postings and emails. Their interaction with the Twitter account and with each other will be the subject of a further study. 


\section{B. Lewis and D. Rush}

An observation based upon a limited amount of data is that users tend to concentrate upon only one or two communication channels.

\section{Conclusion}

The use of social media has rapidly become an accepted way of communicating in many walks of life, although its popular image is still that it is for leisure and entertainment. Here, we have tried to demonstrate that it also has a role in building the networks of practice which can underpin the development of learning professionals. The investigation we have made on the use of Twitter might be replicated using other types of system, but it is more likely that each individual system will attract its own adherents, who find its characteristics most suitable for their needs. This study then can be viewed as part of a broader investigation to specify what facilities need to be provided in social media software to support networked professional development.

\section{References}

Brown, J. S. \& Duguid, P. (2001) 'Knowledge and organization: a social-practice perspective', Organization Science, vol. 12, no. 2, pp. 198-213.

Calishain, T. (2009) 'Using Google's new features to get Twitter information', [online] Available at: http://www.researchbuzz.org/r/?p=825

Cochrane, T. (2010) 'Beyond the Yellow Brick Road: mobile Web 2.0 informing a new institutional e-learning strategy', ALT-J, Research in Learning Technology, vol. 18, no. 3, pp. 221-231.

Cohen, L., Manion, L. \& Morrison, K. (2007) Research Methods in Education, 6th edn, Routledge, Oxford.

Conole, G. \& Alevizo, P. (2010) 'A literature review of the use of Web 2.0 tools in higher education', [online] Available at: http://www.heacademy.ac.uk/assets/EvidenceNet/Cono le_Alevizou_2010.pdf

Cox, A. (2005) 'What are communities of practice? A comparative review of four seminal works', Journal of Information Science, vol. 31, no. 6, pp. 527-540.

Dunlap, J. C. \& Lowenthal, P. R. (2009) 'Tweeting the night away: using Twitter to enhance social presence', Journal of Information Systems Education, vol. 20, no. 2, pp. 129-136.

Ford, N., Bowden, M. \& Beard, J. (2011) 'Learning together: using social media to foster collaboration in higher education', in Higher Education Administration with Social Media (Cutting-edge Technologies in Higher Education, Volume 2), eds. L. A. Wankel \& C. Wankel, Emerald Group, Bingley UK, pp. 105-126.

Fortunato, S. (2010) 'Community detection in graphs', Eprint arXiv:0906.0612v1, [online] Available at: http://arxiv.org

Franklin, T. \& van Harmelen, M. (2007) 'Web 2.0 for content for learning and teaching in higher education', [online] Available at: http://ie-repository.jisc.ac.uk/148/1/web2-contentlearning-and-teaching.pdf

FriendOrFollow. (2010) [online] Available at: http://friendorfollow.com

Gruzd, A., Wellman, B. \& Takhteyev, Y. (2011) 'Imagining Twitter as an imagined community', American Behavioral Scientist, vol. 55, no. 10, pp. 1294-1318.

Hanneman, R. A. \& Riddle, M. (2005) Introduction to Social Network Methods, University of California, Riverside, CA.

Honeycutt, C. \& Herring, S. C. (2009) 'Beyond microblogging: conversation and collaboration via twitter', Proceedings of the 42nd Hawaii International Conference on System Sciences (HICSS), University of Hawaii.

Java, A., et al. (2007) 'Why we Twitter: understanding microblogging usage and communities', 9th International Workshop on Knowledge Discovery on the Web, WebKDD, San Jose, California. 
Jones, Q. (1997) 'Virtual communities, virtual settlements and cyber-archaeology', Journal of Computer Mediated Communication, vol. 3, no. 3.

Jonkeren, E. \& Huysman, M. (2006) 'Identifying Informal Knowledge Networks Through SNA, Revealing the Stickiness of Communities', OLKC 2006 Conference, University of Warwick, Coventry.

Kassens-Noor, E. (2012) 'Twitter as a teaching practice to enhance active and informal learning in higher education: the case of sustainable tweets', Active Learning in Higher Education, vol. 13, no. 1, pp. 9-21.

Kimble, C., Hildreth, P. \& Bourdon, I., eds. (2008) Communities of Practice, Creating Learning Environments for Educators, Volumes 1 and 2, Information Age, Charlotte, NC.

Lave, J. \& Wenger, E. (1991) Situated Learning: Legitimate Peripheral Participation in Communities of Practice, Cambridge University Press, New York.

Little, S. (2008) 'Supporting a dispersed community', in Communities of Practice, Volume 2, eds. C. Kimble, P. Hildreth \& I. Bourdon, Information Age, Charlotte, NC, Ch. 6.

MacDonald, J. \& Hewling, A. (2008) 'Exploring the potential of online communities of practice for distance tutors', in Communities of Practice, Volume 2, eds. C. Kimble, P. Hildreth \& I. Bourdon, Information Age, Charlotte, NC, Ch. 5.

Murillo, E. (2008) 'Searching usenet for virtual communities of practice: using mixed methods to identify the constructs of Wenger's theory', Information Research, vol. 13, no. 4, paper 386, [online] Available at: http://InformationR.net/ir/13-4/paper386.html

Narayan, V. \& Baglow, L. (2010) 'New beginnings: facilitating effective learning through the use of Web 2.0 tools', in Curriculum, Technology \& Transformation for an Unknown Future, eds. C. H. Steel et al., Proceedings ascilite Sydney 2010, pp. 658-667, [online] Available at: http://ascilite.org.au/conferences/sydney10/procs/Narayan-full.pdf

O'Reilly, T. (2005) 'What is web 2.0?' [online] Available at: http://oreilly.com/web2/archive/ what-is-web-20.html

Palla, G. et al. (2005) 'Uncovering the overlapping community structure of complex networks in nature and society', Nature, vol. 435, pp. 814.

RJMetrics. (2010) 'New data on Twitter's users and engagement', [online] Available at: http:// themetricsystem.rjmetrics.com/2010/01/26/new-data-on-twitters-users-and-engagement

Russell, M. A. (2011) Mining the Social Web, O’Reilly Media, Sebastopol, CA.

Schwier, R. A. \& Daniel, B. K. (2008) 'Implications of a virtual learning community model for designing distributed communities of practice in higher education' in Communities of Practice, Volume 2, eds C. Kimble, P. Hildreth \& I. Bourdon, Information Age, Charlotte, NC, Ch. 17.

Twitter. (2010a) 'Twitter API', [online] Available at: http://apiwiki.twitter.com/

Twitter. (2010b) [online] Available at: http://twitter.com

Wasko, M., Tiegland, R. \& Faraj, S. (2009) 'The provision of online public goods: examining social structure in an electronic network of practice', Decision Support Systems, vol. 47, pp. 254-265.

Wenger, E. (1998) Communities of Practice. Learning, Meaning and Identity, Cambridge University Press, Cambridge.

Wenger, E., McDermott, R. \& Snyder, W. M. (2002) Cultivating Communities of Practice, Harvard University Press, Cambridge, MA.

Wenger, E., White, N. \& Smith, J. D. (2009) Digital Habitats. Stewarding Technology for Communities, CPsquare, Portland, Oregon. 